УДК $547.99+630 * 813.1+631.8$

\title{
ИССЛЕДОВАНИЕ ВЛИЯНИЯ КАРБОКСИМЕТИЛИРОВАННОГО РАСТИТЕЛЬНОГО СЫРЬЯ НА АКТИВНОСТЬ ПРОРАСТАНИЯ ЯРОВОЙ МЯГКОЙ ПШЕНИЦЫ
}

\author{
() Е.В. Калюта ${ }^{* 1}$, М.И. Мальцев ${ }^{1}$, В.И. Маркин ${ }^{2}$, И.Б. Катраков ${ }^{2}$ Н.Г. Базарнова
}

\author{
${ }^{1}$ Алтайский государственный аграрный университет, \\ пр. Красноармейский, 98, Барнаул, 656049 (Россия), e-mail: kalyuta75@mail.ru \\ ${ }^{2}$ Алтайский государственный университет, пр. Ленина, 61, Барнаул, 656049 \\ (Россия), e-mail: markin@chem.asu.ru
}

С целью изучения росторегулирующей способности карбоксиметилированного растительного сырья получены водорастворимые $(46,6-75,2 \%)$ карбоксиметилпроизводные с содержанием карбоксиметильных групп 13,3-29,3\%. В результате исследования ростосрегулирующих свойств карбоксиметилированного растительного сырья (древесина сосны, лузга подсолнечника, мякина овса), получены результаты по влиянию вида карбоксиметилированного растительного сырья и способа его внесения на активность прорастания и на начальный рост первых двух листочков яровой мягкой пшеницы сорта Омская-36. Установлено, что сухие препараты, внесенные вместе с семенами, при обеспечении оптимальной влажности, оказывают наибольший ростостимулирующий эффект (20-66\%).

Ключевые слова: растительное сырье, карбоксиметилирование, древесина сосны, лузга подсолнечника, полова овса, яровая пшеница, Омская-36, стимулятор роста.

\section{Введение}

Широкое применение регуляторов роста растений - одно из быстро развивающихся направлений в мировой практике растениеводства. Стимуляторы позволяют увеличивать продуктивность и улучшать качество сельскохозяйственных культур [1-4]. В настоящее время ученые получают физиологические вещества с неизвестным ранее спектром действия на основе природных аминокислот [2], гетероциклических фосфорорганических соединений [3], четвертичных аммониевых соединений [4]. Разрабатываются стимуляторы роста растений на основе природного органического сырья - биостимуляторы [5-8].

Известны методы химического модифицирования растительного сырья без предварительного разде-

Калюта Елена Владимировна - старший преподаватель кафедры химии, кандидат химических наук, e-mail: kalyuta75@mail.ru

Мальиев Михаил Ильич - доцент кафедры общего земледелия и растениеводства, кандидат сельскохозяйственных наук, e-mail: uoshs@mail.ru

Маркин Вадим Иванович - доцент кафедры органической химии, кандидат химических наук, тел.: (3852) 36-95-37, e-mail: markin@ @ chemwood.asu.ru Катраков Игорь Борисович - доцент кафедры органической химии, кандидат химических наук, тел.: (3852) 36-95-37, e-mail: kib-22@yandex.ru Базарнова Наталья Григорьевна - заведующая кафедрой органической химии, профессор, доктор химических наук, тел.: (3852) 36-95-37, e-mail: bazarnova@chemwood.asu.ru ления на отдельные компоненты $[9,10]$. Одним из возможных путей химического модифицирования является карбоксиметилирование растительного сырья с получением водорастворимых полимерных композиций, содержащих в своем составе карбоксиметилированные основные структурные компоненты (целлюлоза, лигнин, гемицеллюлозы), которые обладают комплексом полезных свойств продуктов, которые могут найти применение в различных областях жизнедеятельности человека $[6,11,12]$. Одно из возможных направлений применения карбоксиметилированного растительного сырья - это его использование в качестве вещества, регулирующего рост растений [6-8].

\footnotetext{
* Автор, с которым следует вести переписку.
} 
Цель настоящего исследования - изучение росторегулирующего действия карбоксиметилированного растительного сырья на активность прорастания яровой мягкой пшеницы.

\section{Экспериментальная часть}

Карбоксиметилирование растительного сырья. В качестве исходного растительного сырья использовали древесину сосны (Pinus silvestris), а также отходы растениеводства: поло́ву (мякину) овса (Avenaecarinis L.) и лузгу подсолнечника (Helianthus annuus L.).

Содержание основных структурных компонентов в растительном сырье определяют по стандартным методикам [13]: целлюлозу - по методу Кюршнера (азотно-спиртовым методом), лигнин - с $72 \%$ серной кислотой в модификации Комарова. Содержание целлюлозы в исходной древесине сосны составило $50,5 \pm 0,9 \%$, лигнина $-24,0 \pm 0,3 \%$, в полове овса соответственно $-49,0 \pm 0,7$ и $17,0 \pm 0,4 \%$ и в лузге подсолнечника $-31,3 \pm 0,4$ и $29,3 \pm 0,2 \%$.

Растительное сырье в виде воздушно-сухих опилок фракции 0,3-0,6 мм (влажность 5,5-6,0\%) массой 5,5 кг помещают в реактор РВПЭ-0.2 (ООО «ЮВС», Обнинск). Заранее готовят водный раствор гидроксида натрия (3,2 кг $\mathrm{NaOH}$ в 5 л воды). При постоянном перемешивании со скоростью вращения мешалки 15-25 об/мин, в течение 30 мин добавляют раствор гидроксида натрия к растительному сырью. Температуру реакционной смеси доводят до $60 \pm 5^{\circ} \mathrm{C}$ и выдерживают в течение 1,5 ч. Затем 15 мин при постоянном перемешивании добавляют раствор монохлорацетата натрия (8 кг Na-МХУК в 10 л воды). Температуру реакционной смеси поддерживают при $60 \pm 5^{\circ} \mathrm{C}$, постоянно перемешивая еще 45 мин. После окончания процесса продукты реакции выгружают из реактора в специальный лоток, распределяют слоем 2-5 см и высушивают на воздухе.

Исследование продуктов карбоксиметилирования растительного сырья. Карбоксиметилированную древесину сосны (Na-КМД), карбоксиметилированную полову овса (Na-KMO) и карбоксиметилированную лузгу подсолничника (Na-КМП) анализируют на содержание карбоксиметильных групп (КМГ), вводимых при реакции, методом кондуктометрического титрования [14]. Растворимость полученных образцов определяют в соответствии с методикой, основанной на растворении продукта в воде и последующей фильтрации этого раствора через пористый стеклянный фильтр [15]. Карбоксиметилцеллюлозу (КМЦ) выделяют из карбоксиметилированного растительного сырья 15\% надуксусной кислотой в соответствии с ранее разработанной методикой [16]. Карбоксиметилированный лигнин определяют с $72 \%$ серной кислотой в модификации Комарова [13].

Изучение росторегулирующей активности. Для изучения росторегулирующей активности карбоксиметилированных производных на основе растительного сырья используют яровую мягкую пшеницу сорта Омская-36. Карбоксиметилированные полимерные композиции вносят как в сухом виде, так и в виде суспензии (водного раствора при концентрации растворимой в воде части - 0,2, 0,4 и 0,6 г/л). Массу вещества определяют с учетом растворимости препаратов. В качестве сравнения также изучают воздействие карбоксиметилцеллюлозы (марка КМЦ-М, изготовлена ОАО «БХК», Бийск) в тех же концентрациях.

Семена пшеницы высевают в алюминиевые стаканчики, заполненные песком (массой 60 г, песок предварительно промыт водой и просушен при температуре $150{ }^{\circ} \mathrm{C}$ ). Навеску сухого препарата (Na-КМЦ - 3,6, 7,2 и 10,2 мг; Na-КМД - 7,7, 15,5, 23,2 мг; Na-КМО - 4,8, 9,6, 14,4 мг; Na-КМП - 6,0, 12,1, 18,1 мг) размещают на песок, сверху укладывают семя пшеницы и вдавливают деревянной палочкой на глубину 3 см, затем производят полив дистиллированной водой из расчета 18 мл на образец.

При подготовке водного раствора берут такое же количество исследуемого препарата (из расчета на концентрацию растворимой части - 0,2, 0,4 и 0,6 г/л) и растворяют в течение 1 сут. в 18 мл $\mathrm{H}_{2} \mathrm{O}$. В процессе проведения эксперимента влажность песка в стаканчике поддерживают на уровне 20-30\%. Длительность эксперимента 12 сут. Росторегулирующую активность оценивают по длине первого листочка яровой пшеницы. Статистическую обработку результатов исследований проводят методом дисперсионного анализа по Доспехову [17].

\section{Обсуждение результатов}

В результате карбоксиметилирования растительного сырья получены продукты с содержанием карбоксиметильных групп 13,3-29,3 \% (табл. 1). Полученные образцы карбоксиметилированного растительного сырья в дальнейшем были использованы для испытаний в качестве регуляторов роста растений на примере яровой мягкой пшеницы сорта Омская-36. 
Таблица 1. Состав продуктов карбоксиметилирования различных видов растительного сырья

\begin{tabular}{l|c|c|c|c}
\hline \multirow{2}{*}{$\begin{array}{c}\text { Исходное } \\
\text { растительное сырье }\end{array}$} & \multicolumn{3}{|c}{ Свойства продуктов карбоксиметилирования, \% } \\
\cline { 2 - 5 } & $\begin{array}{c}\text { карбоксиметилиро- } \\
\text { ванная целлюлоза }\end{array}$ & $\begin{array}{c}\text { карбоксиметилиро- } \\
\text { ванный лигнин }\end{array}$ & КМГ & $\begin{array}{c}\text { растворимость } \\
\text { в воде }\end{array}$ \\
\hline Сосна & $32,4 \pm 0,5$ & $16,5 \pm 0,2$ & $29,3 \pm 0,3$ & $46,6 \pm 0,9$ \\
Полова овса & $28,7 \pm 0,4$ & $12,4 \pm 0,3$ & $13,3 \pm 0,3$ & $75,2 \pm 0,8$ \\
Лузга подсолнечника & $21,5 \pm 0,7$ & $17,1 \pm 0,4$ & $19,0 \pm 0,4$ & $59,6 \pm 1,3$ \\
\hline
\end{tabular}

Исследования по изучению влияния карбоксиметилированного растительного сырья на рост яровой пшеницы не выявили закономерностей в интервале изучаемых концентраций, на длину первого листа и корневой системы пшеницы в начальных фазах роста культуры. В то же время прослеживалась достоверная тенденция к увеличению ростовой активности первого листа пшеницы при внесении препаратов карбоксиметилированных отходов растительного сырья в сухом виде в сравнении с контрольным вариантом. Так, без продуктов карбоксиметилированного растительного сырья, длина листочка на 12 сут. после посева

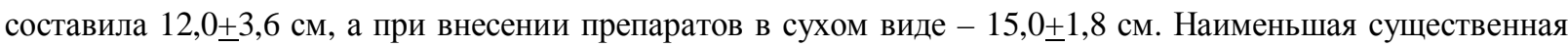
разность при 5\% уровне значимости $\left(\mathrm{HCP}_{05}\right)$ - 2,6 см (табл. 2). Это объясняется тем, что в условиях продолжительности эксперимента концентрация действующего вещества постепенно увеличивается по мере его растворения, а высокая первоначальная концентрация этого вещества в случае использования суспензии может оказывать ингибирующий эффект на прорастание пшеницы.

Проведено исследование влияния вида карбоксиметилированного растительного сырья на активность роста первого листа яровой пшеницы. Показано, что все препараты оказывают влияние на рост, однако наибольшая длина первого листочка пшеницы была отмечена при использовании сухих препаратов на основе подсолнечной лузги. При использовании раствора того же препарата карбоксиметилированной лузги подсолнечника происходит подавление роста (табл. 3.). Этот факт связан как с повышенным содержанием доли карбоксиметилированного лигнина в карбоксиметилированной лузге подсолнечника, по сравнению с другими образцами, так и со строением самого лигнина и его лигноуглеводного комплекса. Ранее было установлено [6], что вероятнее всего именно карбоксиметилированный лигнин оказывает основное ростостимулирующее действие ауксинового типа. Поэтому высокая начальная концентрация карбоксиметилированного лигнина в составе суспензии Na-КМП оказывает значительный ингибирующий эффект. При внесении Na-КМП в сухом виде начальная действующая концентрация карбоксиметилированного лигнина, наоборот, оказывает высокое ростостимулирующее действие.

Таблица 2. Влияние способа внесения карбоксиметилированной древесины сосны на длину первого листочка яровой пшеницы

\begin{tabular}{c|c}
\hline Способ внесения & Длина листочка, см \\
\hline Контроль $\left(\mathrm{H}_{2} \mathrm{O}\right)$ & $12,0 \pm 3,6$ \\
Ка-КМД $(15,5$ мг $)$ & $15,0 \pm 1,8$ \\
Суспензия Na-КМД $(0,4$ г/л) & $13,1 \pm 1,9$ \\
$\mathrm{HCP}_{05}$ & 2,6 \\
\hline
\end{tabular}

Таблица 3. Влияние карбоксиметилированного растительного сырья и способа его внесения на длину первого листочка яровой пшеницы*

\begin{tabular}{|c|c|c|c|c|}
\hline \multirow{3}{*}{ Образец } & \multicolumn{4}{|c|}{ Способ внесения } \\
\hline & \multicolumn{2}{|c|}{ Сухое вещество } & \multicolumn{2}{|c|}{ Суспензия } \\
\hline & длина листа, см & $\begin{array}{l}\text { процент относи- } \\
\text { тельно контроля }\end{array}$ & длина листа, см & $\begin{array}{l}\text { процент относи- } \\
\text { тельно контроля }\end{array}$ \\
\hline Контроль $\left(\mathrm{H}_{2} \mathrm{O}\right)$ & $12,0 \pm 3,6$ & - & $12,0 \pm 3,6$ & - \\
\hline Na-КМЦ & $15,8 \pm 1,9$ & 32 & $14,5 \pm 4,9$ & 21 \\
\hline Na-КМД & $14,4+2,1$ & 20 & $14,3 \pm 2,4$ & 19 \\
\hline Na-KMO & $16,1 \pm 1,2$ & 34 & $13,2 \pm 3,2$ & 10 \\
\hline Na-КМП & $19,9 \pm 6,2$ & 66 & $11,1 \pm 5,3$ & $-7,5$ \\
\hline $\mathrm{HCP}_{05}$ & $3, \overline{3}$ & & 3,8 & \\
\hline
\end{tabular}

Примечание: масса препарата из расчета растворимой части 0,4 г/л 


\section{Заключение}

Таким образом, использование карбоксиметилированного растительного сырья влияет на активность прорастания и начальный рост первых двух листочков яровой мягкой пшеницы сорта Омская-36. Установлено, что сухие препараты, внесенные вместе с семенами, при обеспечении оптимальной влажности, оказывают набольший ростостимулирующий эффект (20-66\%). Использование растворов карбоксиметилированного растительного сырья также приводит к повышению активности роста (10-19\%) яровой пшеницы, но в меньшей степени. Показано, что влияние на росторегулирующую способность зависит не только от способа внесения препарата, но и от вида исходного сырья, его состава и строения.

\section{Список литературы}

1. Пономоренко С.П., Черемха Б.М., Анишин Л.А. Биостимуляторы роста растений нового поколения в технологиях возделывания сельскохозяйственных культур. Киев, 1997. 63 с.

2. Шаповал О.А. Новый регулятор роста растений - Люрастим // Плодородие. 2010. №4. С. 10-12.

3. Фаттахов С.Г. Мелафен - регулятор роста растений нового поколения // Защита и карантин растений. 2011. №11. C. 50.

4. Панина Н.В. Новый регулятор роста - бензихол // Защита и карантин растений. 2005. №12. С. 26.

5. Елькина Е.А., Шубаков А.А., Оводов Ю.С. Влияние пектинов на рост злаковых культур // Химия растительного сырья. 2005. №4. С. 53-56.

6. Маркин В.И. Карбоксиметилирование растительного сырья. Теория и практика : монография. Барнаул, 2010. $167 \mathrm{c}$.

7. Феллер С.В., Маркин В.И., Базарнова Н.Г. Росторегулирующее свойство карбоксиметилированной древесины сосны // Аграрная наука - сельскому хозяйству: сб. статей V Межд. науч.-практ. конф.: в 3 кн. Барнаул, 2010. Кн. 2. С. 119-122.

8. Базарнова Н.Г., Катраков И.Б., Маркин В.И., Верещагина Т.В., Жилина И.Н., Уткова Е.А., Борисова Г.И., Семенков А.А. Росторегулирующие полимерные композиции на основе химически модифицированного растительного сырья для выращивания овощных культур, производимых тепличными технологиями // Вестник алтайской науки. 2013. №1. С. 39-42.

9. Базарнова Н.Г., Катраков И.Б., Маркин В.И. Химическое модифицирование древесины // Российский химический журнал. 2004. Т. XLVIII. №3. С. 108-115.

10. Базарнова Н.Г., Маркин В.И., Колосов П.В., Катраков И.Б., Калюта Е.В., Чепрасова М.Ю. Методы получения лигноуглеводных композиций из химически модифицированного растительного сырья // Российский химический журнал. 2011. T. LV. № 1. C. 4-9.

11. Патент 2130947 (РФ). Способ карбоксиметилированиялигноуглеводных материалов / Галочкин А.И., Маркин В.И., Базарнова Н.Г., Заставенко Н.В., Крестьянникова Н.С.

12. Базарнова Н.Г., Чубик П.С., Хмельницкий А.Г., Галочкин А.И., Маркин В.И. Карбоксиметилированная древесина - химический реагент для приготовления буровых растворов // Журнал прикладной химии. 2001. Т. 74. №4. С. 660-666.

13. Оболенская А.В., Ельницкая 3.П., Леонович А.А. Лабораторные работы по химии древесины и целлюлозы. M., $1991.411 \mathrm{c}$.

14. Eyler R.W., Klug E.D., Diephuis F. Determination of degree of substitution of sodium carboxymethylcellulose // Analytical Chemistry. 1947. Vol. 19, N1. Pp. 24-27.

15. Базарнова Н.Г. Химия древесины и ее основных компонентов. Барнаул, 2002. 52 с.

16. Калюта Е.В., Базарнова Н.Г., Маркин В.И. Влияние продолжительности обработки надуксусной кислотой карбоксиметилированной древесины на свойства выделяемой карбоксиметилцеллюлозы // Химия растительного сырья. 2006. №2. С. 29-31.

17. Доспехов Б.А. Методика полевого опыта (с основами статистической обработки результатов исследований). M., 2011. $352 \mathrm{c}$.

Поступило в редакичию 10 февраля 20132. 
Kaliuta E.V. ${ }^{*}$, Mal'tsev M.I. ${ }^{1}$, Markin V.I. ${ }^{2}$, Katrakov I.B. ${ }^{2}$, Bazarnova N.G. ${ }^{2}$ STUDY OF THE INFLUENCE OF CARBOXYMETHYLATED PLANT MATERIAL ON THE ACTIVITY OF SPRING WHEAT GERMINATION

${ }^{\text {I} A l t a i}$ State Agrarian University, pr. Krasnoarmeiskii, 98, Barnaul,656049, (Russia), e-mail: kalyuta75@mail.ru

${ }^{2}$ Altai State University, pr. Lenina, 61, Barnaul,656049 (Russia), e-mail: markin@chem.asu.ru

Carboxymethylation products containing 13,3-29,3\% carboxymethyl groups and the solubility in water 46,6-75,2\% were obtained for this growth regulating ability.

The results on the effect of type of carboxymethyl plants (pine wood, sunflower husks, oat husks) and a method of making the activity of germination and initial growth of the first two leaves of spring wheat varieties Omskaya-36 were obtained. Dry preparations invected with the seed, while ensuring optimum moisture, act as principle growth-promoting effect (20-66\%) is established.

Keywords: vegetable raw materials, carboxymethylation, pine wood, sunflower husks, chaff oats, spring wheat, Omskaya-36, augmentor.

\section{References}

1. Ponomorenko S.P., Cheremkha B.M., Anishin L.A. Biostimuliatory rosta rastenii novogo pokoleniia v tekhnologiiakh vozdelyvaniia sel'skokhoziaistvennykh kul'tur. [Plant growth stimulators new generation technologies of cultivation of crops]. Kiev, 1997, 63 p. (in Russ.).

2. Shapoval O.A. Plodorodie, 2010, no. 4, pp. 10-12. (in Russ.).

3. Fattakhov S.G. Zashchita i karantin rastenii, 2011, no. 11, p. 50. (in Russ.).

4. Panina N.V. Zashchita i karantin rastenii, 2005, no. 12, p. 26. (in Russ.).

5. El'kina E.A., Shubakov A.A., Ovodov Iu.S. Khimiia rastitel'nogo syr'ia, 2005, no. 4, pp. 53-56. (in Russ.).

6. Markin V.I. Karboksimetilirovanie rastitel'nogo syr'ia. Teoriia i praktika: monografiia. [Carboxymethylation plant materials. Theory and practice: a monograph]. Barnaul, 2010. 167 p. (in Russ.).

7. Feller S.V., Markin V.I., Bazarnova N.G. Agrarnaia nauka - sel'skomu khoziaistvu: sbornik statei V mezhdunarodnoi nauchno-prakticheskoi konferentsii. [Agricultural science - agriculture: a collection of articles V International Scientific and Practical Conference]. Barnaul, 2010, part 2. pp. 119-122. (in Russ.).

8. Bazarnova N.G., Katrakov I.B., Markin V.I., Vereshchagina T.V., Zhilina I.N., Utkova E.A., Borisova G.I., Semenkov A.A. Vestnik altaiskoi nauki, 2013, no. 1, pp. 39-42. (in Russ.).

9. Bazarnova N.G., Katrakov I.B., Markin V.I. Rossiiskii khimicheskii zhurnal, 2004, vol. XLVIII, no. 3, pp. $108-115$. (in Russ.).

10. Bazarnova N.G., Markin V.I., Kolosov P.V., Katrakov I.B., Kaliuta E.V., Cheprasova M.Iu. Rossiiskii khimicheskii zhurnal, 2011, vol. LV, no. 1, pp. 4-9. (in Russ.).

11. Patent 2130947 (RU). 1999. (in Russ.).

12. Bazarnova N.G., Chubik P.S., Khmel'nitskii A.G., Galochkin A.I., Markin V.I. Zhurnal prikladnoi khimii, 2001, vol. 74, no. 4, pp. 660-666. (in Russ.).

13. Obolenskaia A.V., El'nitskaia Z.P., Leonovich A.A. Laboratornye raboty po khimii drevesiny $i$ tselliulozy. [Laboratory work on the chemistry of wood and cellulose]. Moscow, 1991, 411 p. (in Russ.).

14. Eyler R.W., Klug E.D., Diephuis F. Analytical Chemistry, 1947, vol. 19, no. 1, pp. 24-27.

15. Bazarnova N.G. Khimiia drevesiny i ee osnovnykh komponentov. [Wood Chemistry and its main components]. Barnaul, 2002, 52 p. (in Russ.).

16. Kaliuta E.V., Bazarnova N.G., Markin V.I. Khimiia rastitel'nogo syr'ia, 2006, no. 2, pp. 29-31.

17. Dospekhov B.A. Metodika polevogo opyta (s osnovami statisticheskoi obrabotki rezul'tatov issledovanii). [Methods of field experience (with the fundamentals of statistical analysis of the results of research)]. Moscow, 2011, $352 \mathrm{p}$. (in Russ.).

\footnotetext{
* Corresponding author.
} 
